\title{
The Hippocampus
}

Marion Wright* et al.

\begin{abstract}

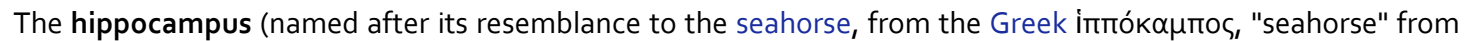

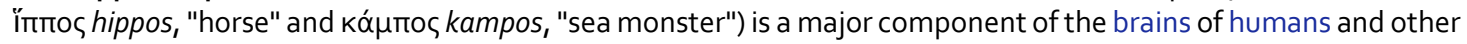
vertebrates. Humans and other mammals have two hippocampi, one in each side of the brain. It belongs to the limbic system and plays important roles in the consolidation of information from short-term memory to long-term memory and spatial memory that enables navigation. The hippocampus is located under the cerebral cortex; (allocortical) ${ }^{[1][2][3]}$ and in primates it is located in the medial temporal lobe, underneath the cortical surface. It contains two main interlocking parts: the hippocampus proper (also called Ammon's horn) ${ }^{[4]}$ and the dentate gyrus.

In Alzheimer's disease (and other forms of dementia), the hippocampus is one of the first regions of the brain to suffer damage; short-term memory loss and disorientation are included among the early symptoms. Damage to the hippocampus can also result from oxygen starvation (hypoxia), encephalitis, or medial temporal lobe epilepsy. People with extensive, bilateral hippocampal damage may experience anterograde amnesia (the inability to form and retain new memories).

In rodents as model organisms, the hippocampus has been studied extensively as part of a brain system responsible for spatial memory and navigation. Many neurons in the rat and mouse hippocampus respond as place cells: that is, they fire bursts of action potentials when the animal passes through a specific part of its environment. Hippocampal place cells interact extensively with head direction cells, whose activity acts as an inertial compass, and conjecturally with grid cells in the neighboring entorhinal cortex.

Since different neuronal cell types are neatly organized into layers in the hippocampus, it has frequently been used as a model system for studying neurophysiology. The form of neural plasticity known as long-term potentiation (LTP) was first discovered to occur in the hippocampus and has often been studied in this structure. LTP is widely believed to be one of the main neural mechanisms by which memories are stored in the brain.
\end{abstract}

\section{Name}

The earliest description of the ridge running along the floor of the temporal horn of the lateral ventricle comes from the Venetian anatomist Julius Caesar Aranzi (1587), who likened it first to a silkworm and then to a seahorse (Latin: hippocampus from Greek: ïrnoৎ, "horse" and кó $\mu \pi$ \%, "sea monster"). The German anatomist Duvernoy (1729), the first to illustrate the structure, also wavered between "seahorse" and "silkworm." "Ram's horn" was proposed by the Danish anatomist Jacob Winsløw in 1732; and a decade later his fellow Parisian, the surgeon de Garengeot, used "cornu Ammonis" - horn of (the ancient Egyptian god) Amun, ${ }^{[5]}$ who was often represented as having a ram's head. ${ }^{[6]}$ This has survived in abbreviated form as $C A$ in naming the subfields of the hippocampus.

*Author correspondence: by online form

Licensed under: CC-BY-SA

Received 10-10-2016; accepted 11-03-2017
Another reference appeared with the term pes hippocampi, which may date back to Diemerbroeck in 1672, introducing a comparison with the shape of the folded back forelimbs and webbed feet of the mythological hippocampus, a sea monster with a horse's forequarters and a fish's tail. The hippocampus was then described as pes hippocampi major, with an adjacent bulge in the occipital horn, described as the pes hippocampi minor and later renamed as the calcar avis. ${ }^{[5][7]}$ The renaming of the hippocampus as hippocampus major, and the calcar avis as hippocampus minor, has been attributed to Félix Vicq-d'Azyr systematising nomenclature of parts of the brain in 1786. Mayer mistakenly used the term hippopotamus in 1779, and was followed by some other authors until Karl Friedrich Burdach resolved this error in 1829. In 1861 the hippocampus minor became the centre of a dispute over human evolution between Thomas Henry Huxley and Richard Owen, satirised as 


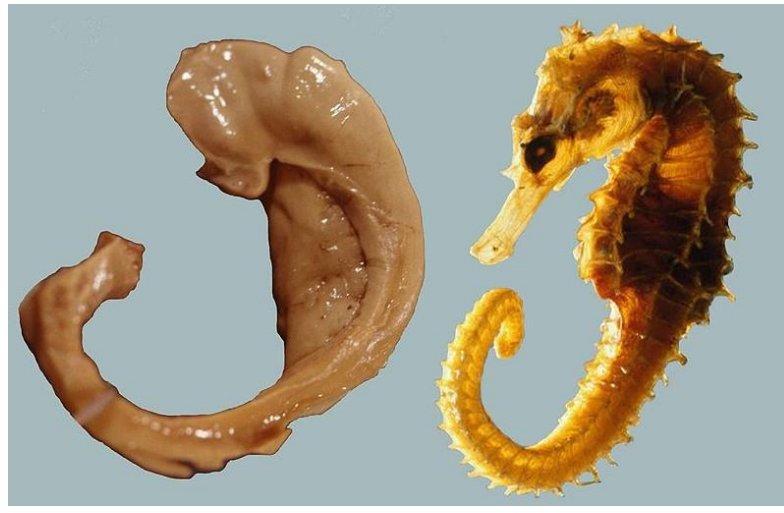

Figure 1 | The human hippocampus and fornix compared with a seahorse. László Seress, modified by AnthonyHCole, CC-BYSA 3.0

the Great Hippocampus Question. The term hippocampus minor fell from use in anatomy textbooks, and was officially removed in the Nomina Anatomica of 1895. ${ }^{[8]}$ Today, the structure is just called the hippocampus, ${ }^{[5]}$ with the term Cornu Ammonis surviving in the names of the hippocampal subfields CA1-CA4. ${ }^{[9]}$

The term limbic system was introduced in 1952 by Paul MacLean ${ }^{[10]}$ to describe the set of structures that line the edge of the cortex (Latin limbus meaning border): These include the hippocampus, cingulate cortex, olfactory cortex, and amygdala. Paul MacLean later suggested that the limbic structures comprise the neural basis of emotion. The hippocampus is anatomically connected to parts of the brain that are involved with emotional behavior-the septum, the hypothalamic mammillary body, and the anterior nuclear complex in the thalamus, and is generally accepted to be part of the limbic system. ${ }^{[11]}$

\section{Anatomy}

The hippocampus can be seen as a ridge of gray matter tissue, elevating from the floor of each lateral ventricle in the region of the inferior or temporal horn. ${ }^{[12][13]}$ This ridge can also be seen as an inward fold of the archicortex into the medial temporal lobe. ${ }^{[14]}$ The hippocampus can only be seen in dissections as it is concealed by the parahippocampal gyrus. ${ }^{[14][15]}$ The cortex thins from six layers to the three or four layers that make up the hippocampus. ${ }^{[16]}$

The term hippocampal formation is used to refer to the hippocampus proper and its related parts. However, there is no consensus as to what parts are included. Sometimes the hippocampus is said to include the dentate gyrus and the subiculum. Some references include the dentate gyrus and the subiculum in the hippocampal formation, ${ }^{[1]}$ and others also include the presubiculum, parasubiculum, and entorhinal cortex. ${ }^{[2]}$ The neural layout and pathways within the hippocampal formation are very similar in all mammals. ${ }^{[3]}$

The hippocampus, including the dentate gyrus, has the shape of a curved tube, which has been compared to a seahorse, and a ram's horn (Cornu Ammonis). Its abbreviation $C A$ is used in naming the hippocampal subfields: CA1, CA2, CA3, and CA4. ${ }^{[15]}$ It can be distinguished as an area where the cortex narrows into a single layer of densely packed pyramidal neurons, which curl into a tight $U$ shape. One edge of the "U," - CA4, is embedded into the backward-facing, flexed dentate gyrus. The hippocampus is described as having an anterior and posterior part (in primates) or a ventral and dorsal part in other animals. Both parts are of similar composition but belong to different neural circuits. ${ }^{[17]}$ In the rat, the two hippocampi resemble a pair of bananas, joined at the stems by the commissure of fornix (also called the hippocampal commissure). In primates, the part of the hippocampus at the bottom, near the base of the temporal lobe, is much broader than the part at the top.

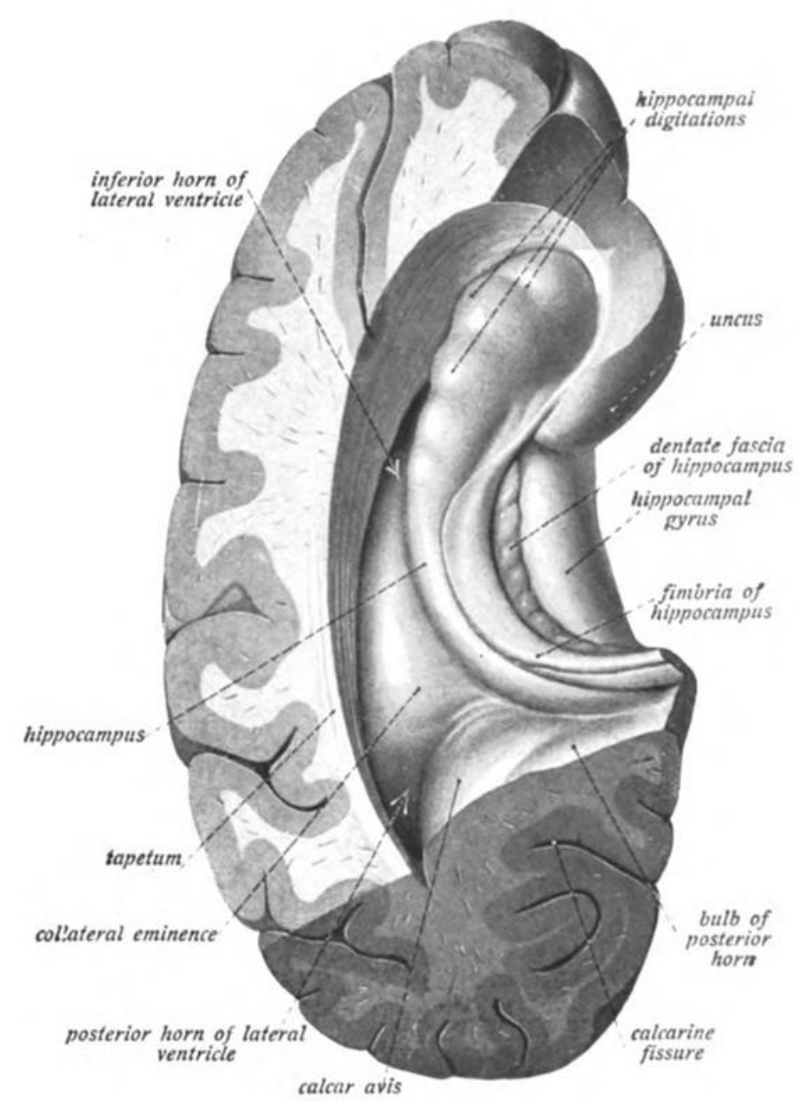

Figure 2 | Cross-section of cerebral hemisphere showing structure and location of hippocampus. Johannes Sobotta, public domain 


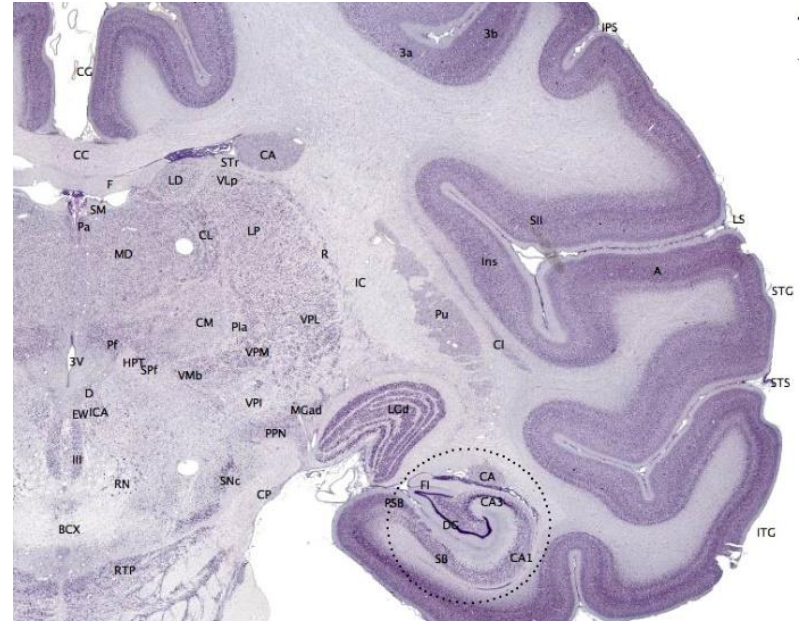

Figure 3 | Coronal section of the brain of a macaque monkey, showing hippocampus (circled). brainmaps.org, CC-BY-SA 3.0

This means that in cross-section the hippocampus can show a number of different shapes, depending on the angle and location of the cut.

In cross-section of the hipppocampus, including the dentate gyrus, several layers will be shown. The dentate gyrus has three layers of cells (or four if the hilus is included). The layers are from the outer in - the molecular layer, the inner molecular layer, the granular layer, and the hilus. The CA3 in the hippocampus proper has the following cell layers known as strata: lacunosum-moleculare, radiatum, lucidum, pyramidal, and oriens. CA2 and CA1 also have four each of these layers and not the lucidum stratum.

The input to the hippocampus (from varying cortical and subcortical structures) comes from the entorhinal cortex via the perforant path. The entorhinal cortex $(E C)$ is strongly and reciprocally connected with many cortical and subcortical structures as well as with the brainstem. Different thalamic nuclei, (from the anterior and midline groups), the medial septal nucleus, the supramamillary nucleus of the hypothalamus, and the raphe nuclei and locus coeruleus of the brainstem all send axons to the EC, so that it serves as the interface between the neocortex and the other connections, and the hippocampus.

The EC, is located in the parahippocampal gyrus, ${ }^{[2]}$ a cortical region adjacent to the hippocampus. ${ }^{[18]}$ This gyrus conceals the hippocampus. The parahippocampal gyrus also includes the perirhinal cortex which plays an important role in the visual recognition of complex objects. There is also substantial evidence that it makes a contribution to memory, which can be distinguished from the contribution of the hippocampus. It is apparent that complete amnesia occurs only when both the hippocampus and the parahippocampus are damaged. ${ }^{[18]}$

\section{Circuitry}

The perforant path is the main output pathway of the entorhinal cortex (EC). The flow of information in the hippocamous is largely unidirectional. Axons from the pyramidal cells (in EC layer II) perforate the subiculum to project mainly to the granular layer in the dentate gyrus (first synaptic connection). Some axons project to CA3 and a lesser number project to CA1. The dentate granule cell axons, called mossy fibers, pass on the information, to the dendrites of CA3 pyramidal cells (second synaptic connection). From there, CA3 axons called Schaffer collaterals leave the deep part of the cell body and loop up to the apical dendrites and then extend to CA1. Axons from CA1 then project back to the entrorhinal coretex (third synaptic connection) completing the trisynaptic loop or circuit. ${ }^{[19]}$

Basket cells in CA3 receive excitatory input from the pyramidal cells and then give an inhibitory feedback to the pyramidal cells. This recurrent inhibition is a simple feedback circuit that can dampen excitatory responses in the hippocampus. The pyramidal cells gives a recurrent excitation which is an important mechanism found in some memory processing microcircuits. ${ }^{[20]}$

Several other connections play important roles in hippocampal function. ${ }^{[15]}$ Beyond the output to the EC, additional output pathways go to other cortical areas including the prefrontal cortex. A major output goes via the fornix to the lateral septal area and to the mammillary body of the hypothalamus (which the fornix interconnects with the hippocampus). ${ }^{[14]}$ The hippocampus receives modulatory input from the serotonin, norepinephrine, and dopamine systems, and from the nucleus reuniens of the thalamus to field CA1. A very important projection comes from the medial septal nucleus, which sends cholinergic, and gamma amino butyric acid

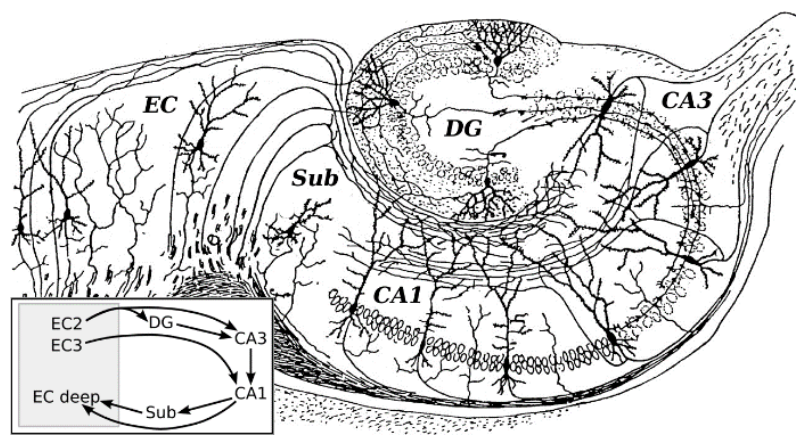

Figure 4 | Basic circuit of the hippocampus, DG: dentate gyrus. Sub: subiculum. EC: entorhinal cortex. Santiago Ramón y Cajal, modified by William Skaggs, public domain 
(GABA) stimulating fibers (GABAergic fibers) to all parts of the hippocampus. The inputs from the medial septal nucleus play a key role in controlling the physiological state of the hippocampus; destruction of this nucleus abolishes the hippocampal theta rhythm and severely impairs certain types of memory. ${ }^{[21]}$

\section{Functions}

\section{Hippocampal regions}

Areas of the hippocampus are shown to be functionally and anatomically distinct. The dorsal hippocampus $(\mathrm{DH})$, ventral hippocampus $(\mathrm{VH})$ and intermediate hippocampus serve different functions, project with differing pathways, and have varying degrees of place cells. ${ }^{[23]}$ The dorsal hippocampus serves for spatial memory, verbal memory, and learning of conceptual information. Using the radial arm maze, lesions in the DH were shown to cause spatial memory impairment while $\mathrm{VH}$ lesions did not. Its projecting pathways include the medial septal nucleus and supramammillary nucleus. ${ }^{[24]}$ The dorsal hippocampus also has more place cells than both the ventral and intermediate hippocampal regions. ${ }^{[25]}$

The intermediate hippocampus has overlapping characteristics with both the ventral and dorsal hippocampus. ${ }^{[23]}$ Using anterograde tracing methods, Cenquizca and Swanson (2007) located the moderate projections to two primary olfactory cortical areas and prelimbic areas of the medial prefrontal cortex. This region has the smallest number of place cells. The ventral hippocam-

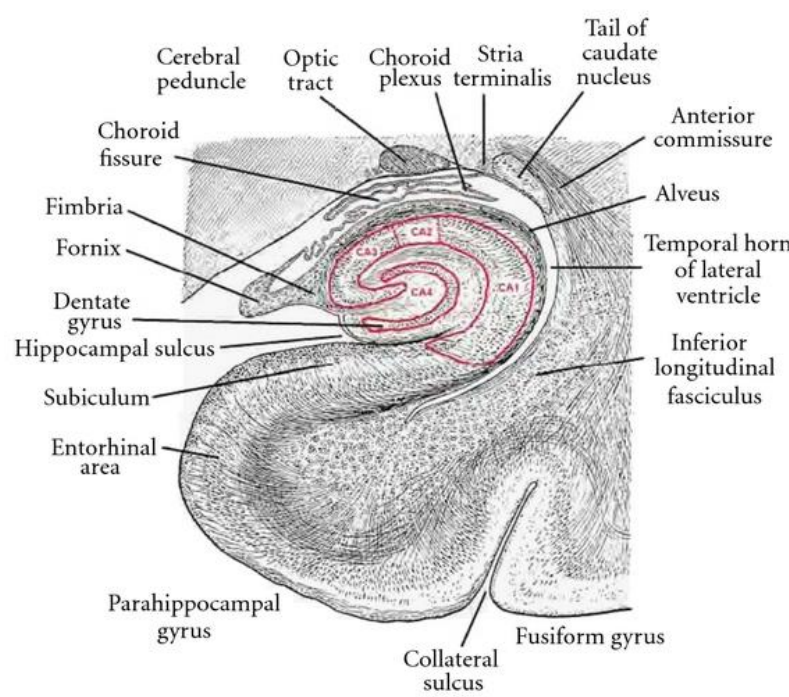

Figure 5 | Hippocampal location and regions. [22] John Kiernan CC-BY-SA 4.0 pus functions in fear conditioning and affective processes. ${ }^{[26]}$ Anagnostaras et al. (2002) showed that alterations to the ventral hippocampus reduced the amount of information sent to the amygdala by the dorsal and ventral hippocampus, consequently altering fear conditioning in rats. ${ }^{[27]}$

Historically, the earliest widely held hypothesis was that the hippocampus is involved in olfaction. ${ }^{[28]}$ This idea was cast into doubt by a series of anatomical studies that did not find any direct projections to the hippocampus from the olfactory bulb. ${ }^{[29]}$ However, later work did confirm that the olfactory bulb does project into the ventral part of the lateral entorhinal cortex, and field CA1 in the ventral hippocampus sends axons to the main olfactory bulb, ${ }^{[30]}$ the anterior olfactory nucleus, and to the primary olfactory cortex. There continues to be some interest in hippocampal olfactory responses, in particular the role of the hippocampus in memory for odors, but few specialists today believe that olfaction is its primary function. ${ }^{[31][32]}$

\section{Theories of hippocampal functions}

Over the years, three main ideas of hippocampal function have dominated the literature: inhibition response, memory, and space. The behavioral inhibition theory (caricatured by John O'Keefe and Lynn Nadel as "slam on the brakes!"' ${ }^{[33]}$ was very popular up to the 1960 s. It derived much of its justification from two observations: first, that animals with hippocampal damage tend to be hyperactive; second, that animals with hippocampal damage often have difficulty learning to inhibit responses that they have previously been taught, especially if the response requires remaining quiet as in a passive avoidance test. Jeffrey Gray developed this line of thought into a full-fledged theory of the role of the hippocampus in anxiety. ${ }^{[34]}$ The inhibition theory is currently the least popular of the three. ${ }^{[35]}$

The second major line of thought relates the hippocampus to memory. Although it had historical precursors, this idea derived its main impetus from a famous report by William Beecher Scoville and Brenda Milner ${ }^{[36]}$ describing the results of surgical destruction of the hippocampi (in an attempt to relieve epileptic seizures), in Henry Molaison, ${ }^{[37]}$ known until his death in 2008 as "Patient H.M." The unexpected outcome of the surgery was severe anterograde and partial retrograde amnesia; Molaison was unable to form new episodic memories after his surgery and could not remember any events that occurred just before his surgery, but he did retain memories of events that occurred many years earlier extending back into his childhood. This case attracted such widespread professional interest that Molaison 
became the most intensively studied subject in medical history. ${ }^{[38]}$ In the ensuing years, other patients with similar levels of hippocampal damage and amnesia (caused by accident or disease) have also been studied, and thousands of experiments have studied the physiology of activity-driven changes in synaptic connections in the hippocampus. There is now universal agreement that the hippocampi play some sort of important role in memory; however, the precise nature of this role remains widely debated. ${ }^{[39][40]}$

The third important theory of hippocampal function relates the hippocampus to space. The spatial theory was originally championed by O'Keefe and Nadel, who were influenced by E.C. Tolman's theories about "cognitive maps" in humans and animals. O'Keefe and his student Dostrovsky in 1971 discovered neurons in the rat hippocampus that appeared to them to show activity related to the rat's location within its environment. ${ }^{[41]}$ Despite skepticism from other investigators, O'Keefe and his co-workers, especially Lynn Nadel, continued to investigate this question, in a line of work that eventually led to their very influential 1978 book The Hippocampus as a Cognitive Map. ${ }^{[42]}$ There is now almost universal agreement that hippocampal function plays an important role in spatial coding, but the details are widely debated. ${ }^{[43]}$

Later research has focused on trying to bridge the disconnect between the two main views of hippocampal function as being split between memory and spatial cognition. In some studies these areas have been expanded to the point of near convergence. In an attempt to reconcile the two disparate views it is suggested that a broader view of the hippocampal function is taken and seen to have a role that encompasses both the organisation of experience (mental mapping), (as per Tolman's original concept in 1948) and the directional behaviour seen as being involved in all areas of cognition. So that the function of the hippocampus can be viewed as a broader system that incorporates both the memory and the spatial perspectives in its role that involves the use of a wide scope of cognitive maps. ${ }^{[44]}$ This relates to the purposive behaviorism born of Tolman's original goal of identifying the complex cognitive mechanisms and purposes that guided behaviour. ${ }^{[45]}$

It has also been proposed that the spiking activity of hippocampal neurons is associated spatially, and it was suggested that the mechanisms of memory and planning both evolved from mechanisms of navigation and that their neuronal algorithms were basically the same. ${ }^{[46]}$

Many studies have made use of neuroimaging techniques such as functional magnetic resonance imaging
(fMRI) and a functional role in approach-avoidance conflict has been noted. The anterior hippocampus is seen to be involved in decision-making under approachavoidance conflict processing. It is suggested that the memory, spatial cognition, and conflict processing functions may be seen as working together and not mutually exclusive. ${ }^{[47]}$

\section{Role in memory}

Psychologists and neuroscientists generally agree that the hippocampus plays an important role in the formation of new memories about experienced events (episodic or autobiographical memory). ${ }^{[40][48]}$ Part of this function is hippocampal involvement in the detection of new events, places and stimuli. ${ }^{[49]}$ Some researchers regard the hippocampus as part of a larger medial temporal lobe memory system responsible for general declarative memory (memories that can be explicitly verbalized-these would include, for example, memory for facts in addition to episodic memory). ${ }^{[39]}$

Due to bilateral symmetry the brain has a hippocampus in each cerebral hemisphere. If damage to the hippocampus occurs in only one hemisphere, leaving the structure intact in the other hemisphere, the brain can retain near-normal memory functioning. ${ }^{[50]}$ Severe damage to the hippocampi in both hemispheres results in profound difficulties in forming new memories (anterograde amnesia) and often also affects memories formed before the damage occurred (retrograde amnesia). Although the retrograde effect normally extends many years back before the brain damage, in some cases older memories remain. This retention of older memories leads to the idea that consolidation over time involves the transfer of memories out of the hippocampus to other parts of the brain. ${ }^{[48]}$ Experiments using intrahippocampal transplantation of hippocampal cells in primates with neurotoxic lesions of the hippocampus have shown that the hippocampus is required for the formation and recall, but not the storage, of memories. ${ }^{[51]}$

Damage to the hippocampus does not affect some types of memory, such as the ability to learn new skills (playing a musical instrument or solving certain types of puzzles, for example). This fact suggests that such abilities depend on different types of memory (procedural memory) and different brain regions. Furthermore, amnesic patients frequently show "implicit" memory for experiences even in the absence of conscious knowledge. For example, patients asked to guess which of two faces they have seen most recently may give the correct answer most of the time in spite of stating that they have never seen either of the faces before. Some 
researchers distinguish between conscious recollection, which depends on the hippocampus, and familiarity, which depends on portions of the medial temporal lobe. ${ }^{[52]}$

\section{Role in spatial memory and navigation}

Studies on freely moving rats and mice have shown many hippocampal neurons to act as place cells that cluster in place fields, and these fire bursts of action potentials when the animal passes through a particular location. This place-related neural activity in the hippocampus has also been reported in monkeys that were moved around a room whilst in a restraint chair. ${ }^{[53]}$ However, the place cells may have fired in relation to where the monkey was looking rather that to its actual location in the room. ${ }^{[54]}$ Over many years, many studies have been carried out on place-responses in rodents, that have given a large amount of information. ${ }^{[43]}$ Place cell responses are shown by pyramidal cells in the hippocampus and by granule cells in the dentate gyrus. Other cells in smaller proportion are inhibitory interneurons and these often show place-related variations in their firing-rate which are much weaker. There is little if any spatial topography in the representation; in general, cells lying next to each other in the hippocampus have uncorrelated spatial firing patterns. Place cells are typically almost silent when a rat is moving around outside the place field but reach sustained rates as high as $40 \mathrm{~Hz}$, when the rat is near the center. Neural activity sampled from 30 to 40 randomly chosen place cells carries enough information to allow a rat's location to be reconstructed with high confidence. The size of place fields varies in a gradient along the length of the hippocampus, with cells at the dorsal end showing the smallest fields, cells near the center showing larger fields, and cells at the ventral tip showing fields that cover the entire environment. ${ }^{[43]}$ In some cases, the firing rate of hippocampal cells depends not only on place but also on the direction a rat is moving, the destination toward which it is traveling, or other task-related variables. ${ }^{[55]}$

In humans, cells with location-specific firing patterns have been reported during a study of patients with drug-resistant epilepsy. They were undergoing an invasive procedure to localize the source of their seizures, with a view to surgical resection. The patients had diagnostic electrodes implanted in their hippocampus and then used a computer to move around in a virtual reality town. ${ }^{[56]}$ Similar brain imaging studies in navigation have shown the hippocampus to be active. A study was carried out on taxi drivers. London's black cab drivers need to learn the locations of a large number of places and the fastest routes between them in order to pass a strict test known as The Knowledge in order to gain a

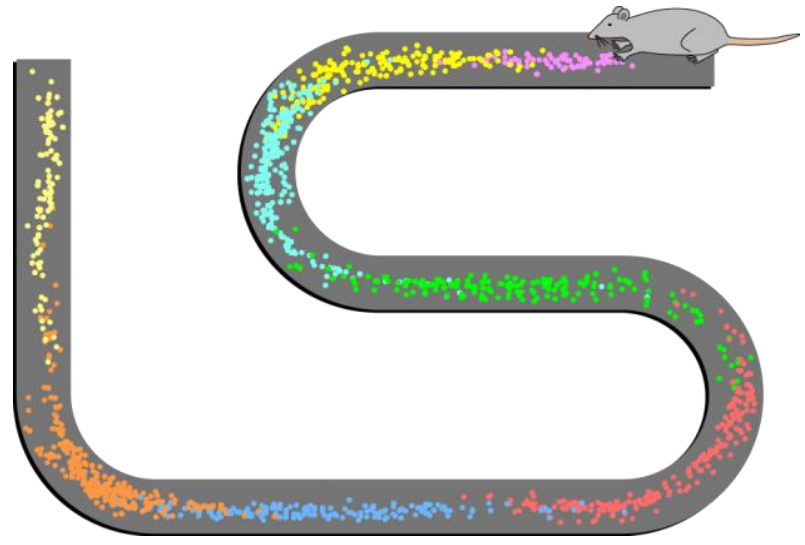

Figure 6 | Spatial firing patterns of 8 place cells recorded from the CA1 layer of a rat. The rat ran back and forth along an elevated track, stopping at each end to eat a small food reward. Dots indicate positions where action potentials were recorded, with color indicating which neuron emitted that action potential. Stuart Layton, CC-BY-SA 3.0

license to operate. A study showed that the posterior part of the hippocampus is larger in these drivers than in the general public, and that a positive correlation exists between the length of time served as a driver and the increase in the volume of this part. It was also found the total volume of the hippocampus was unchanged, as the increase seen in the posterior part was made at the expense of the anterior part, which showed a relative decrease in size. There have been no reported adverse effects from this disparity in hippocampal proportions. ${ }^{[57]}$

There are several navigational cells in the brain that are either in the hippocampus itself or are strongly connected to it, such as the speed cells present in the medial enterorhinal cortex. Together these cells form a network that serves as spatial memory. The first of such cells discovered in the 1970s were the place cells, which led to the idea of the hippocampus acting to give a neural representation of the environment in a cognitive map. ${ }^{[58]}$ When the hippocampus is dysfunctional, orientation is affected; people may have difficulty in remembering how they arrived at a location and how to proceed further. Getting lost is a common symptom of amnesia. ${ }^{[59]}$ Studies with animals have shown that an intact hippocampus is required for initial learning and longterm retention of some spatial memory tasks, in particular ones that require finding the way to a hidden goal. ${ }^{[60][61][62][63]}$ Other cells have been discovered since the finding of the place cells in the rodent brain that are either in the hippocampus or the entorhinal cortex. These have been assigned as head direction cells, grid cells and boundary cells. ${ }^{[43][64]}$ Speed cells are thought to provide input to the hippocampal grid cells. 


\section{Role in approach-avoidance conflict pro- cessing}

Approach-avoidance conflict happens when a situation is presented that can either be rewarding or punishing, and the ensuing decision making has been associated with anxiety. ${ }^{[65]} \mathrm{fMRI}$ findings from studies in approachavoidance decision-making found evidence for a functional role that is not explained by either long-term memory or spatial cognition. Overall findings showed that the anterior hippocampus is sensitive to conflict, and that it may be part of a larger cortical and subcortical network seen to be important in decision making in uncertain conditions. ${ }^{[65]}$

A review makes reference to a number of studies that show the involvement of the hippocampus in conflict tasks. The authors suggest that a challenge is to understand how conflict processing relates to the functions of spatial navigation and memory and how all of these functions need not be mutually exclusive. ${ }^{[66]}$

\section{Physiology}

The hippocampus shows two major "modes" of activity, each associated with a distinct pattern of neural population activity and waves of electrical activity as measured by an electroencephalogram (EEG). These modes are named after the EEG patterns associated with them: theta and large irregular activity (LIA). The main characteristics described below are for the rat, which is the animal most extensively studied. ${ }^{[67]}$

The theta mode appears during states of active, alert behavior (especially locomotion), and also during REM (dreaming) sleep. ${ }^{[68]}$ In the theta mode, the EEG is dominated by large regular waves with a frequency range of 6 to $9 \mathrm{~Hz}$, and the main groups of hippocampal neurons (pyramidal cells and granule cells) show sparse population activity, which means that in any short time interval, the great majority of cells are silent, while the small remaining fraction fire at relatively high rates, up to 50 spikes in one second for the most active of them. An active cell typically stays active for half a second to a few seconds. As the rat behaves, the active cells fall silent and new cells become active, but the overall percentage of active cells remains more or less constant. In many situations, cell activity is determined largely by the spatial location of the animal, but other behavioral variables also clearly influence it.

The LIA mode appears during slow-wave (non-dreaming) sleep, and also during states of waking immobility such as resting or eating ${ }^{[68]}$ In the LIA mode, the EEG is dominated by sharp waves that are randomly timed

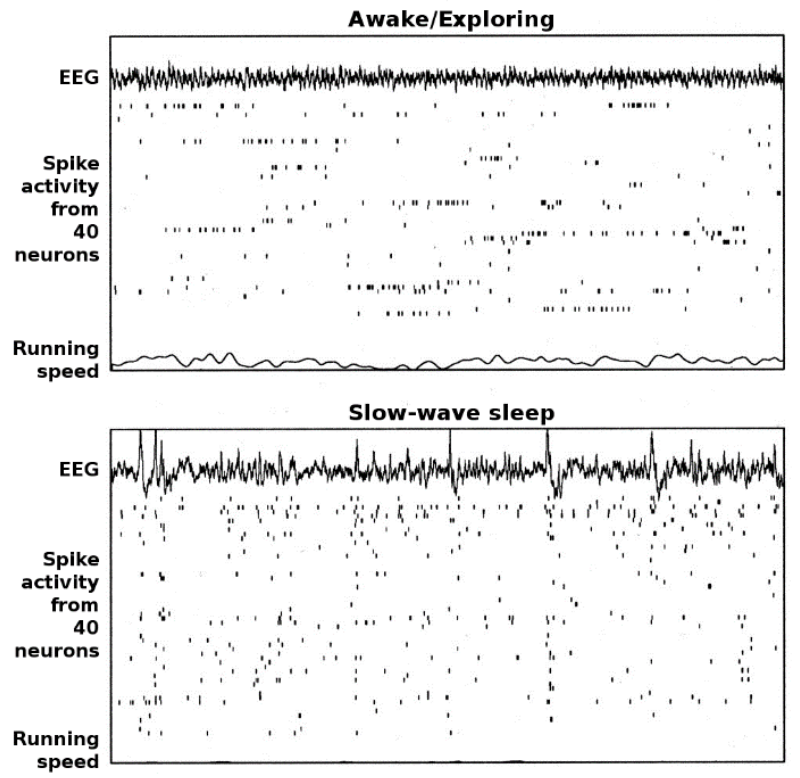

Figure 7 | Examples of rat hippocampal EEG and CA1 neural activity in the theta (awake/behaving) and LIA (slow-wave sleep) modes. Each plot shows 20 seconds of data, with a hippocampal EEG trace at the top, spike rasters from 40 simultaneously recorded CA1 pyramidal cells in the middle (each raster line represents a different cell), and a plot of running speed at the bottom. The top plot represents a time period during which the rat was actively searching for scattered food pellets. For the bottom plot the rat was asleep.

William Skaggs, public domain

large deflections of the EEG signal lasting for 25-50 milliseconds. Sharp waves are frequently generated in sets, with sets containing up to 5 or more individual sharp waves and lasting up to $500 \mathrm{~ms}$. The spiking activity of neurons within the hippocampus is highly correlated with sharp wave activity. Most neurons decrease their firing rate between sharp waves; however, during a sharp wave, there is a dramatic increase of firing rate in up to $10 \%$ of the hippocampal population

These two hippocampal activity modes can be seen in primates as well as rats, with the exception that it has been difficult to see robust theta rhythmicity in the primate hippocampus. There are, however, qualitatively similar sharp waves and similar state-dependent changes in neural population activity. ${ }^{[69]}$

\section{Theta rhythm}

Because of its densely packed neural layers, the hippocampus generates some of the largest EEG signals as theta waves of any brain structure, which generate the hippocampal theta rhythm. ${ }^{[70]}$ In some situations the EEG is dominated by regular waves at 3 to $10 \mathrm{~Hz}$, often continuing for many seconds. These reflect subthreshold membrane potentials and strongly modulate the 


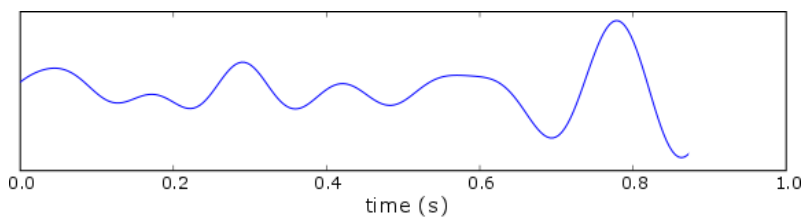

Figure 8 | Example of a one-second EEG theta wave. Hugo Gamboa, CC-BY-SA 3.0

spiking of hippocampal neurons and synchronise across the hippocampus in a travelling wave pattern. ${ }^{[71]}$ The trisynaptic circuit is a relay of neurotransmission in the hippocampus that interacts with many brain regions. From rodent studies it has been proposed that the trisynaptic circuit generates the hippocampal theta rhythm. ${ }^{[72]}$

Theta rhythmicity is very obvious in rabbits and rodents and also clearly present in cats and dogs. Whether theta can be seen in primates is not yet clear. ${ }^{[73]}$ In rats (the animals that have been the most extensively studied), theta is seen mainly in two conditions: first, when an animal is walking or in some other way actively interacting with its surroundings; second, during REM sleep. ${ }^{[74]}$ The function of theta has not yet been convincingly explained although numerous theories have been proposed. ${ }^{[67]}$ The most popular hypothesis has been to relate it to learning and memory. An example would be the phase with which theta rhythms, at the time of stimulation of a neuron, shape the effect of that stimulation upon its synapses. What is meant here is that theta rhythms may affect those aspects of learning and memory that are dependent upon synaptic plasticity. ${ }^{[75]}$ It is well established that lesions of the medial septumthe central node of the theta system-cause severe disruptions of memory. However, the medial septum is more than just the controller of theta; it is also the main source of cholinergic projections to the hippocampus. ${ }^{[15]}$ It has not been established that septal lesions exert their effects specifically by eliminating the theta rhythm. ${ }^{[76]}$

\section{Sharp waves}

During sleep or during resting when an animal is not engaged with its surroundings, the hippocampal EEG shows a pattern of irregular slow waves, somewhat larger in amplitude than theta waves. This pattern is occasionally interrupted by large surges called sharp waves. ${ }^{[77]}$ These events are associated with bursts of spike activity lasting 50 to 100 milliseconds in pyramidal cells of CA3 and CA1. They are also associated with short-lived high-frequency EEG oscillations called "ripples", with frequencies in the range 150 to $200 \mathrm{~Hz}$ in rats, and together they are known as sharp waves and ripples. Sharp waves are most frequent during sleep when they occur at an average rate of around 1 per second (in rats) but in a very irregular temporal pattern. Sharp waves are less frequent during inactive waking states and are usually smaller. Sharp waves have also been observed in humans and monkeys. In macaques, sharp waves are robust but do not occur as frequently as in rats. ${ }^{[69]}$

One of the most interesting aspects of sharp waves is that they appear to be associated with memory. Wilson and McNaughton 1994, ${ }^{[78]}$ and numerous later studies, reported that when hippocampal place cells have overlapping spatial firing fields (and therefore often fire in near-simultaneity), they tend to show correlated activity during sleep following the behavioral session. This enhancement of correlation, commonly known as reactivation, has been found to occur mainly during sharp waves. ${ }^{[79]}$ It has been proposed that sharp waves are, in fact, reactivations of neural activity patterns that were memorized during behavior, driven by strengthening of synaptic connections within the hippocampus. ${ }^{[80]}$ This idea forms a key component of the "two-stage memory" theory, advocated by Buzsáki and others, which proposes that memories are stored within the hippocampus during behavior and then later transferred to the neocortex during sleep. Sharp waves in Hebbian theory are seen as persistently repeated stimulations by presynaptic cells, of postsynaptic cells that are suggested to drive synaptic changes in the cortical targets of hippocampal output pathways. ${ }^{[81]}$ Suppression of sharp waves and ripples in sleep or during immobility can interfere with memories expressed at the level of the behavior, ${ }^{[82][83]}$ nonetheless, the newly formed CA1 place cell code can re-emerge even after a sleep with abolished sharp-waves and ripples in spatially nondemanding tasks. ${ }^{[84]}$

\section{Long-term potentiation}

Since at least the time of Ramon y Cajal (1852-1934), psychologists have speculated that the brain stores memory by altering the strength of connections between neurons that are simultaneously active. ${ }^{\left[{ }^{85]}\right]}$ This idea was formalized by Donald Hebb in 1949, ${ }^{[86]}$ but for many years remained unexplained. In 1973, Tim Bliss and Terje Lømo described a phenomenon in the rabbit hippocampus that appeared to meet Hebb's specifications: a change in synaptic responsiveness induced by brief strong activation and lasting for hours or days or longer. ${ }^{[87]}$ This phenomenon was soon referred to as long-term potentiation, abbreviated LTP. As a candidate mechanism for long-term memory, LTP has since been studied intensively, and a great deal has been learned about it. However, the complexity and variety of the intracellular signalling cascades that can trigger 
LTP is acknowledged as preventing a more complete understanding. ${ }^{[88]}$

The hippocampus is a particularly favorable site for studying LTP because of its densely packed and sharply defined layers of neurons, but similar types of activitydependent synaptic change have also been observed in many other brain areas. ${ }^{\left[{ }^{[9]}\right.}$ The best-studied form of LTP has been seen in CA1 of the hippocampus and occurs at synapses that terminate on dendritic spines and use the neurotransmitter glutamate. ${ }^{\left[{ }^{90]}\right.}$ The synaptic changes depend on a special type of glutamate receptor, the N-methyl-D-aspartate (NMDA) receptor, a cell surface receptor which has the special property of allowing calcium to enter the postsynaptic spine only when presynaptic activation and postsynaptic depolarization occur at the same time. ${ }^{[91]}$ Drugs that interfere with NMDA receptors block LTP and have major effects on some types of memory, especially spatial memory. Genetically modified mice that are modified to disable the LTP mechanism, also generally show severe memory deficits. ${ }^{[91]}$

\section{Pathology}

\section{Aging}

Age-related conditions such as Alzheimer's disease and other forms of dementia (for which hippocampal disruption is one of the earliest signs ${ }^{[92]}$ ) have a severe impact on many types of cognition, but even normal aging is associated with a gradual decline in some types of memory, including episodic memory and working memory (or short-term memory). Because the hippocampus is thought to play a central role in memory, there has been considerable interest in the possibility that age-related declines could be caused by hippocampal deterioration. ${ }^{[93]}$ Some early studies reported substantial loss of neurons in the hippocampus of elderly people, but later studies using more precise techniques found only minimal differences. ${ }^{[93]}$ Similarly, some MRI studies have reported shrinkage of the hippocampus in elderly people, but other studies have failed to reproduce this finding. There is, however, a reliable relationship between the size of the hippocampus and memory performance: where there is age-related shrinkage, memory performance will be impaired. ${ }^{[94]}$ There are also reports that memory tasks tend to produce less hippocampal activation in the elderly than in the young ${ }^{\left[{ }^{94]}\right.}$ Furthermore, a randomized control trial published in 2011 found that aerobic exercise could increase the size of the hippocampus in adults aged 55 to 80 and also improve spatial memory. ${ }^{[95]}$

\section{Effects of cortisol}

The hippocampus contains high levels of glucocorticoid receptors, which make it more vulnerable to long-term stress than most other brain areas. ${ }^{[96]}$ There is evidence that humans having experienced severe, long-lasting traumatic stress show atrophy of the hippocampus more than of other parts of the brain. ${ }^{[97]}$ These effects show up in post-traumatic stress disorder ${ }_{,}{ }^{[98]}$ and they may contribute to the hippocampal atrophy reported in schizophrenia ${ }^{[99][100]}$ and severe depression. ${ }^{[101]} \mathrm{A}$ recent study has also revealed atrophy as a result of depression, but this can be stopped with anti-depressants even if they are not effective in relieving other symptoms. ${ }^{[102]}$

Chronic stress resulting in elevated levels of glucocorticoids, notably of cortisol, is seen to be a cause of neuronal atrophy in the hippocampus. This atrophy results in a smaller hippocampal volume which is also seen in Cushing's syndrome. The higher levels of cortisol in Cushing's syndrome is usually the result of medications taken for other conditions. ${ }^{[103][104]}$ Neuronal loss also occurs as a result of impaired neurogenesis. Another factor that contributes to a smaller hippocampal volume is that of dendritic retraction where dendrites are shortened in length and reduced in number, in response to increased glucocorticoids. This dendritic retraction is reversible ${ }^{[104]}$ After treatment with medication to reduce cortisol in Cushing's syndrome, the hippocampal volume is seen to be restored by as much as $10 \%$. ${ }^{[103]}$ This change is seen to be due to the reforming of the dendrites. ${ }^{[104]}$ This dendritic restoration can also happen when stress is removed. There is, however, evidence derived mainly from studies using rats that stress occurring shortly after birth can affect hippocampal function in ways that persist throughout life. ${ }^{[105]}$

Sex-specific responses to stress have also been demonstrated in the rat, to have an effect on the hippocampus. Chronic stress in the male rat showed dendritic retraction and cell loss in the CA3 region but this was not shown in the female. This was thought to be due to neuroprotective ovarian hormones. ${ }^{[106][107]}$

\section{Epilepsy}

The hippocampus is one of the few brain regions where new neurons are generated. This process of neurogenesis is confined to the dentate gyrus. ${ }^{[109]}$ The production of new neurons can be positively affected by exercise or negatively affected by epileptic seizures. ${ }^{[109]}$ Seizures in temporal lobe epilepsy can affect the normal development of new neurons and can cause tissue damage. Hippocampal sclerosis is the most common type of such tissue damage. ${ }^{[110]}$ It is not yet clear, however, whether 


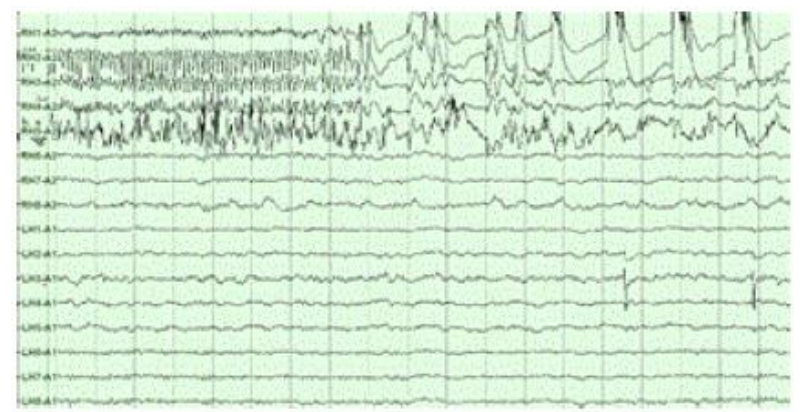

Figure 9 | An EEG showing epilepsy right-hippocampal seizure onset. ${ }^{[108]}$ Francisco Velasco et al, CC-BY-SA 4.0

the epilepsy is usually caused by hippocampal abnormalities or whether the hippocampus is damaged by cumulative effects of seizures. ${ }^{[111]}$ However, in experimental settings where repetitive seizures are artificially induced in animals, hippocampal damage is a frequent result. This may be a consequence of the concentration of excitable glutamate receptors in the hippocampus. Hyperexcitability can lead to cytotoxicity and cell death. ${ }^{[104]}$ It may also have something to do with the hippocampus being a site where new neurons continue to be created throughout life, ${ }^{[109]}$ and to abnormalities in this process. ${ }^{[104]}$

\section{Schizophrenia}

The causes of schizophrenia are not well understood, but numerous abnormalities of brain structure have been reported. The most thoroughly investigated alterations involve the cerebral cortex, but effects on the hippocampus have also been described. Many reports have found reductions in the size of the hippocampus in schizophrenic subjects. ${ }^{[12]}$ The left hippocampus seems to be affected more than the right. ${ }^{[112]}$ The changes noted have largely been accepted to be the result of abnormal development. It is unclear whether hippocampal alterations play any role in causing the psychotic symptoms that are the most important feature of schizophrenia. It has been suggested that on the basis of experimental work using animals, hippocampal dysfunction might produce an alteration of dopamine release in the basal ganglia, thereby indirectly affecting the integration of information in the prefrontal cortex. ${ }^{[113]}$ It has also been suggested that hippocampal dysfunction might account for the disturbances in longterm memory frequently observed. ${ }^{[114]}$

MRI studies have found a smaller brain volume and larger ventricles in people with schizophrenia. Researchers do not know if the shrinkage is from the schizophrenia or from the medication. ${ }^{[115][116]}$ The hippocampus and thalamus have been shown to be reduced in

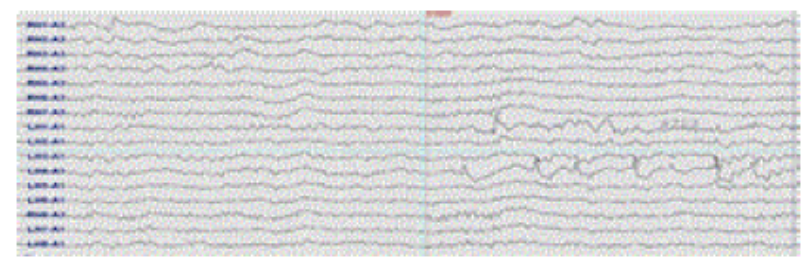

Figure 10 | An EEG showing epilepsy left-hippocampal seizure onset. ${ }^{[108]}$ Francisco Velasco et al, CC-BY-SA 4.0

volume; and the volume of the globus pallidus is increased. Cortical patterns are altered, and a reduction in the volume and thickness of the cortex particularly in the frontal and temporal lobes has been noted. It has further been proposed that many of the changes seen are present at the start of the disorder which gives weight to the theory that there is abnormal neurodevelopment. ${ }^{[117]}$

The hippocampus has been seen as central to the pathology of schizophrenia, both in the neural and physiological effects. ${ }^{[112]}$ It has been generally accepted that there is an abnormal synaptic connectivity underlying schizophrenia. Several lines of evidence implicate changes in the synaptic organization and connectivity, in and from the hippocampus ${ }^{[112]}$ Many studies have found dysfunction in the synaptic circuitry within the hippocampus and its activity on the prefrontal cortex. The glutamergic pathways have been seen to be largely affected. The subfield CA1 is seen to be the least involved of the other subfields, ${ }^{[112][118]}$ and CA4 and the subiculum have been reported elsewhere as being the most implicated areas. ${ }^{[118]}$ The review concluded that the pathology could be due to genetics, faulty neurodevelopment or abnormal neural plasticity. It was further concluded that schizophrenia is not due to any known neurodegenerative disorder. ${ }^{[112]}$

\section{Transient global amnesia}

Transient global amnesia is a dramatic, sudden, temporary, near-total loss of short-term memory. Various causes have been hypothesized including ischemia, epilepsy, migraine ${ }^{[119]}$ and disturbance of cerebral venous blood flow, ${ }^{[120]}$ leading to ischemia of structures such as the hippocampus that are involved in memory. ${ }^{[121]}$

There has been no scientific proof of any cause. However diffusion weighted MRI studies taken from 12-24 hours following an episode has shown there to be small dot-like lesions in the hippocampus. These findings have suggested a possible implication of CA1 neurons made vulnerable by metabolic stress. ${ }^{[119]}$ 


\section{Other animals}

The hippocampus has a generally similar appearance across the range of mammals, from monotremes such as the echidna to primates such as humans. ${ }^{[122]}$ The hippocampal-size-to-body-size ratio broadly increases, being about twice as large for primates as for the echidna. It does not, however, increase at anywhere close to the rate of the neocortex-to-body-size ratio. Therefore, the hippocampus takes up a much larger fraction of the cortical mantle in rodents than in primates. In adult humans the volume of the hippocampus on each side of the brain is about 3.0 to $3.5 \mathrm{~cm}^{3}$ as compared to 320 to $420 \mathrm{~cm}^{3}$ for the volume of the neocortex. ${ }^{[123]}$

There is also a general relationship between the size of the hippocampus and spatial memory. When comparisons are made between similar species, those that have a greater capacity for spatial memory tend to have larger hippocampal volumes. ${ }^{[124]}$ This relationship also extends to sex differences; in species where males and females show strong differences in spatial memory ability they also tend to show corresponding differences in hippocampal volume. ${ }^{[125]}$

Non-mammalian species do not have a brain structure that looks like the mammalian hippocampus, but they have one that is considered homologous to it. The hippocampus, as pointed out above, is in essence part of the allocortex. Only mammals have a fully developed cortex, but the structure it evolved from, called the pallium, is present in all vertebrates, even the most primitive ones such as the lamprey or hagfish. ${ }^{[126]}$ The pallium is usually divided into three zones: medial, lateral and dorsal. The medial pallium forms the precursor of the hippocampus. It does not resemble the hippocampus visually because the layers are not warped into an $S$ shape or enfolded by the dentate gyrus, but the homology is indicated by strong chemical and functional affinities. There is now evidence that these hippocampallike structures are involved in spatial cognition in birds, reptiles, and fish. ${ }^{[127]}$

In birds, the correspondence is sufficiently well established that most anatomists refer to the medial pallial zone as the "avian hippocampus". ${ }^{[128]}$ Numerous species of birds have strong spatial skills, in particular those that cache food. There is evidence that food-caching birds have a larger hippocampus than other types of birds and that damage to the hippocampus causes impairments in spatial memory. ${ }^{[129]}$

The story for fish is more complex. In teleost fish (which make up the great majority of existing species), the forebrain is distorted in comparison to other types of

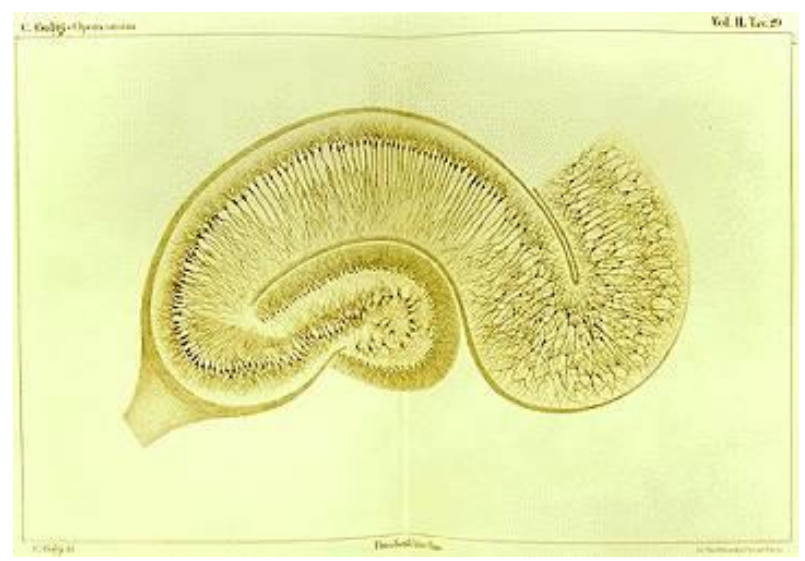

Figure 11 | Drawing of a hippocampus stained using the silver nitrate method. Camillo Golgi, public domain

vertebrates: Most neuroanatomists believe that the teleost forebrain is in essence everted, like a sock turned inside-out, so that structures that lie in the interior, next to the ventricles, for most vertebrates, are found on the outside in teleost fish, and vice versa. ${ }^{[130]}$ One of the consequences of this is that the medial pallium ("hippocampal" zone) of a typical vertebrate is thought to correspond to the lateral pallium of a typical fish. Several types of fish (particularly goldfish) have been shown experimentally to have strong spatial memory abilities, even forming "cognitive maps" of the areas they inhabit. ${ }^{[124]}$ There is evidence that damage to the lateral pallium impairs spatial memory. ${ }^{[131][132]}$

It is not yet known whether the medial pallium plays a similar role in even more primitive vertebrates, such as sharks and rays, or even lampreys and hagfish. Some types of insects, and molluscs such as the octopus, also have strong spatial learning and navigation abilities, but these appear to work differently from the mammalian spatial system, so there is as yet no good reason to think that they have a common evolutionary origin; nor is there sufficient similarity in brain structure to enable anything resembling a "hippocampus" to be identified in these species. Some have proposed, however, that the insect's mushroom bodies may have a function similar to that of the hippocampus. ${ }^{[133]}$

\section{Acknowledgements}

Conflict of Interest: none declared.

\section{References}

1. Martin, JH (2003). "Lymbic system and cerebral circuits for emotions, learning, and memory". Neuroanatomy: text and atlas (third ed.). McGrawHill Companies. p. 382. ISBN 0-07-121237-X.

2. Amaral, D; Lavenex, P (2007). "Hippocampal neuroanatomy". In Anderson, P; Morris, R; Amaral, D et al.. The hippocampus book (first ed.). New York: Oxford University Press. p. 37. ISBN 978-0-19-510027-3. 
3. Anderson, P; Morris, R; Amaral, D; Bliss, T; O'Keefe, J (2007). "The hippocampal formation". In Anderson, $\mathrm{P}$; Morris, $\mathrm{R}_{i}$ Amaral, D et al.. The hippocampus book (first ed.). New York: Oxford University Press. p. 3. ISBN 978-0-19-510027-3.

4. Pearce JM (Sep 2001). "Ammon's horn and the hippocampus". Journal of Neurology, Neurosurgery, and Psychiatry 71 (3): 351. doi:10.1136/jnnp.71.3.351. PMID 11511709. PMC 1737533.

5. Duvernoy, HM (2005). "Introduction". The Human Hippocampus (3rd ed.). Berlin: Springer-Verlag. p. 1. ISBN 3-540-23191-9.

6. "cornu ammonis". TheFreeDictionary.com.

7. Owen, CM; Howard, A; Binder, DK (December 2009). "Hippocampus minor, calcar avis, and the Huxley-Owen debate.". Neurosurgery 65 (6): 1098-104; discussion 1104-5. doi:10.1227/01.neu.0000359535.84445.0b. PMID 19934969

8. Gross CG (Oct 1993). "Hippocampus minor and man's place in nature: a case study in the social construction of neuroanatomy". Hippocampus 3 (4): 403-416. doi:10.1002/hipo.450030403. PMID 8269033.

9. Wechsler RT, Morss, AM, Wustoff, CJ, \& Caughey, AB (2004). Blueprints notes \& cases: Neuroscience. Oxford: Blackwell Publishing. p. 37. ISBN 14051-0349-3.

10. Kazlev, M.Alan. "Paul MacLean's triune brain hypothesis". www. kheper.net

11. "Chapter 9: Limbic System". www.dartmouth.edu.

12. Andersen, Per; Morris, Richard; Amaral, David; Bliss, Tim; O'Keefe, John (2 November 2006). "The Hippocampus Book". Oxford University Press.

13. Alberts, Daniel Albert (2012). Dorland's illustrated medical dictionary. (32nd ed. ed.). Philadelphia, PA: Saunders/Elsevier. p. 860. ISBN 978-1-41606257-8.

14. Purves, Dale (2011). Neuroscience (5th ed.). Sunderland, Mass.: Sinauer. pp. 730-735. ISBN 978-0-87893-695-3.

15. Amaral, Di Lavenex P (2006). "Ch 3. Hippocampal Neuroanatomy". In Andersen P. The Hippocampus Book. Oxford University Press. ISBN 978-019-510027-3.

16. Purves, Dale (2011). Neuroscience (5. ed. ed.). Sunderland, Mass.: Sinauer. p. 590. ISBN 978-087893-695-3.

17. Moser MB, Moser El (1998). "Functional differentiation in the hippocampus". Hippocampus 8 (6): 608-19. doi:10.1002/(SICI)10981063(1998)8:6<608::AID-HIPO3>3.0.CO;2-7. PMID 9882018.

18. Eichenbaum $H$, Yonelinas AP, Ranganath C (2007). "The medial temporal lobe and recognition memory". Annual Review of Neuroscience 30: 123-52. doi:10.1146/annurev.neuro.30.051606.094328. PMID 17417939. PMC 2064941.

19. Purves, Dale (2011). Neuroscience (5th ed.). Sunderland, Mass.: Sinauer. p. 171. ISBN 978-0-87893-695-3.

20. "Introduction to Neurons and Neuronal Networks | Section 1, Intro Chapter | Neuroscience Online: An Electronic Textbook for the Neurosciences | Department of Neurobiology and Anatomy - The University of Texas Medical School at Houston". neuroscience.uth.tmc.edu.

21. Winson J (Jul 1978). "Loss of hippocampal theta rhythm results in spatial memory deficit in the rat". Science 201 (4351): 160-63. doi:10.1126/science.663646. PMID 663646.

22. Kiernan, J. A. (2012). "Anatomy of the Temporal Lobe". Epilepsy Research and Treatment 2012: 1-12. doi:10.1155/2012/176157. ISSN 2090-1348.

23. Fanselow MS, Dong HW (Jan 2010). "Are the dorsal and ventral hippocampus functionally distinct structures?". Neuron 65 (1): 7-19. doi:10.1016/j.neuron.2009.11.031. PMID 20152109. PMC 2822727.

24. Pothuizen $\mathrm{HH}$, Zhang WN, Jongen-Rêlo AL, Feldon J, Yee BK (Feb 2004). "Dissociation of function between the dorsal and the ventral hippocampus in spatial learning abilities of the rat: a within-subject, within-task comparison of reference and working spatial memory". The European Journal of Neuroscience19 (3): 705-712. doi:10.1111/j.0953816X.2004.03170.x. PMID 14984421.

25. Jung MW, Wiener SI, MCNaughton BL (Dec 1994). "Comparison of spatial firing characteristics of units in dorsal and ventral hippocampus of the rat". The Journal of Neuroscience 14 (12): 7347-7356. PMID 7996180.

26. Cenquizca LA, Swanson LW (Nov 2007). "Spatial organization of direct hippocampal field CA1 axonal projections to the rest of the cerebral cortex". Brain Research Reviews 56 (1): 1-26. doi:10.1016/j.brainresrev.2007.05.002. PMID 17559940. PMC 2171036.

27. Anagnostaras SG, Gale GD, Fanselow MS (2002). "The hippocampus and Pavlovian fear conditioning: reply to Bast et al". Hippocampus 12 (4): 561565. doi:10.1002/hipo.10071. PMID 12201641.

28. Finger, S (2001). "Defining and controlling the circuits of emotion". Origins of neuroscience: a history of explorations into brain function. Oxford/NewYork: Oxford University Press. p. 286. ISBN 0-19-506503-4.

29. Finger, S (2001). Origins of Neuroscience: A History of Explorations Into Brain Function. Oxford University Press US. ISBN 978-0-19-514694-3.
30. "Extrinsic projections from area CA1 of the rat hippocampus: olfactory, cortical, subcortical, and bilateral hippocampal formation projections". Journal of Comparative Neurology. 1990. doi:10.1002/cne.903020308.

31. Eichenbaum, H; Otto TA; Wible CG; Piper JM (1991). "Ch 7. Building a model of the hippocampus in olfaction and memory". In Davis JL. Olfaction. MIT Press. ISBN 978-0-262-04124-9.

32. Vanderwolf $\mathrm{CH}$ (Dec 2001). "The hippocampus as an olfacto-motor mechanism: were the classical anatomists right after all?". Behavioural Brain Research 127 (1-2): 25-47. doi:10.1016/S0166-4328(01)00354-0. PMID 11718883.

33. Nadel L, O'Keefe J, Black A (Jun 1975). "Slam on the brakes: a critique of Altman, Brunner, and Bayer's response-inhibition model of hippocampal function". Behavioral Biology 14 (2): 151-62. doi:10.1016/S00916773(75)90148-0. PMID 1137539.

34. Gray, JA; McNaughton N (2000). The Neuropsychology of Anxiety: An Enquiry into the Functions of the Septo-Hippocampal System. Oxford University Press

35. Best PJ, White AM (1999). "Placing hippocampal single-unit studies in a historical context". Hippocampus 9 (4): 346-51. doi:10.1002/(SICI)10981063(1999)9:4<346::AID-HIPO2>3.0.CO;2-3. PMID 10495017.

36. Scoville WB, Milner B (Feb 1957). "Loss of recent memory after bilateral hippocampal lesions". Journal of Neurology, Neurosurgery, and Psychiatry 20 (1): 11-21. doi:10.1136/jnnp.20.1.11. PMID 13406589. PMC 497229.

37. Carey, B (2008-12-04). "H. M., an Unforgettable Amnesiac, Dies at 82". The New York Times. Retrieved 2009-04-27.

38. Squire LR (Jan 2009). "The legacy of patient H.M. for neuroscience". Neuron61 (1): 6-9. doi:10.1016/j.neuron.2008.12.023. PMID 19146808. PMC 2649674

39. Squire LR (Apr 1992). "Memory and the hippocampus: a synthesis from findings with rats, monkeys, and humans". Psychological Review 99 (2): 195-231. doi:10.1037/0033-295X.99.2.195. PMID 1594723.

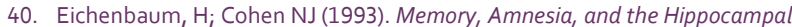
System. MIT Press.

41. O'Keefe J, Dostrovsky J (Nov 1971). "The hippocampus as a spatial map. Preliminary evidence from unit activity in the freely-moving rat". Brain Research34 (1): 171-75. doi:10.1016/0006-8993(71)90358-1. PMID 5124915.

42. O'Keefe, J; Nadel L (1978). The Hippocampus as a Cognitive Map. Oxford University Press.

43. Moser El, KropffE, Moser MB (2008). "Place cells, grid cells, and the brain's spatial representation system". Annual Review of Neuroscience31: 69 -89. doi:10.1146/annurev.neuro.31.061307.090723. PMID 18284371.

44. Schiller, D.; Eichenbaum, H.; Buffalo, E. A.; Davachi, L.; Foster, D. J.i Leutgeb, S.; Ranganath, C. (2015). "Memory and Space: Towards an Understanding of the Cognitive Map". Journal of Neuroscience 35 (41): 13904-13911. doi:10.1523/JNEUROSCI.2618-15.2015. ISSN 0270-6474.

45. Eichenenbaum $\mathrm{H}$ (2001). "The hippocampus and declarative memory: Cognitive mechanisms and neural codes". Behavioural Brain Research 127 (1): 199-207.

46. Buzsáki, György; Moser, Edvard I (2013). "Memory, navigation and theta rhythm in the hippocampal-entorhinal system". Nature Neuroscience 16 (2): 130-138. doi:10.1038/nn.3304. ISSN 1097-6256.

47. Ito, R; Lee, AC (15 October 2016). "The role of the hippocampus in approach-avoidance conflict decision-making: Evidence from rodent and human studies.". Behavioural Brain Research 313: 345-57. doi:10.1016/j.bbr.2016.07.039. PMID 27457133.

48. Squire, LR; Schacter DL (2002). The Neuropsychology of Memory. Guilford Press.

49. VanElzakker $M$, Fevurly $R$, Breindel $T$, Spencer RL (Dec 2008). "Environmental novelty is associated with a selective increase in Fos expression in the output elements of the hippocampal formation and the perirhinal cortex". Learning \& Memory 15 (12): 899-908. doi:10.1101/lm.1196508. PMID 19050162. PMC 2632843.

50. Di Gennaro G, Grammaldo LG, Quarato PP, Esposito V, Mascia A, Sparano A, Meldolesi GN, Picardi A (Jun 2006). "Severe amnesia following bilateral medial temporal lobe damage occurring on two distinct occasions". Neurological Sciences 27 (2): 129-33. doi:10.1007/s10072-006-0614-y. PMID 16816912.

51. Virley, et al (1999). "Primary CA1 and conditionally immortal MHP36 cell grafts restore conditional discrimination learning and recall in marmosets after excitotoxic lesions of the hippocampal CA1 field.". Brain 122: 23212335. doi:10.1093/brain/122.12.2321.

52. Diana RA, Yonelinas AP, Ranganath C (Sep 2007). "Imaging recollection and familiarity in the medial temporal lobe: a three-component model". Trends in Cognitive Sciences 11 (9): 379-86. doi:10.1016/j.tics.2007.08.001. PMID 17707683. 
53. Matsumura N, Nishijo H, Tamura R, Eifuku S, Endo S, Ono T (Mar 1999). "Spatial- and task-dependent neuronal responses during real and virtual translocation in the monkey hippocampal formation". The Journal of Neuroscience 19 (6): 2381-93. PMID 10066288.

54. Rolls ET, Xiang JZ (2006). "Spatial view cells in the primate hippocampus and memory recall". Reviews in the Neurosciences 17 (1-2): 175-200. doi:10.1515/REVNEURO.2006.17.1-2.175. PMID 16703951

55. Smith DM, Mizumori SJ (2006). "Hippocampal place cells, context, and episodic memory". Hippocampus 16 (9): 716-29. doi:10.1002/hipo.20208. PMID 16897724.

56. Ekstrom AD, Kahana MJ, Caplan JB, Fields TA, Isham EA, Newman EL, Fried I (Sep 2003). "Cellular networks underlying human spatial navigation" (PDF). Nature 425 (6954): 184-88. doi:10.1038/nature01964. PMID 12968182.

57. Maguire EA, Gadian DG, Johnsrude IS, Good CD, Ashburner J, Frackowiak RS, Frith CD (Apr 2000). "Navigation-related structural change in the hippocampi of taxi drivers". Proceedings of the National Academy of Sciences of the United States of America 97 (8): 4398-403. doi:10.1073/pnas.070039597. PMID 10716738. PMC 18253.

58. O'Keefe, J; Nadel L (1978). The Hippocampus as a Cognitive Map. Oxford University Press.

59. Chiu YC, Algase D, Whall A, Liang J, Liu HC, Lin KN, Wang PN (2004). "Getting lost: directed attention and executive functions in early Alzheimer's disease patients". Dementia and Geriatric Cognitive Disorders 17 (3): 174-80. doi:10.1159/000076353. PMID 14739541.

60. Morris RG, Garrud P, Rawlins JN, O'Keefe J (Jun 1982). "Place navigation impaired in rats with hippocampal lesions". Nature 297 (5868): 681-83. doi:10.1038/297681a0. PMID 7088155 .

61. Sutherland RJ, Kolb B, Whishaw IQ (Aug 1982). "Spatial mapping: definitive disruption by hippocampal or medial frontal cortical damage in the rat". Neuroscience Letters 31 (3): 271-6. doi:10.1016/03043940(82)90032-5. PMID 7133562.

62. Sutherland RJ, Weisend MP, Mumby D, Astur RS, Hanlon FM, Koerner A, Thomas MJ, Wu Y, Moses SN, Cole C, Hamilton DA, Hoesing JM (2001). "Retrograde amnesia after hippocampal damage: recent vs. remote memories in two tasks". Hippocampus 11 (1): 27-42. doi:10.1002/10981063(2001)11:1<27::AID-HIPO1017>3.0.CO;2-4. PMID 11261770.

63. Clark RE, Broadbent NJ, Squire LR (2005). "Hippocampus and remote spatial memory in rats". Hippocampus 15 (2): 260-72. doi:10.1002/hipo.20056. PMID 15523608. PMC 2754168.

64. Solstad T, Boccara CN, Kropff E, Moser MB, Moser El (Dec 2008). "Representation of geometric borders in the entorhinal cortex". Science 322 (5909): 1865-68. doi:10.1126/science.1166466. PMID 19095945.

65. O'Neil, EB; Newsome, RN; Li, IH; Thavabalasingam, S; Ito, R; Lee, AC (11 November 2015). "Examining the Role of the Human Hippocampus in Approach-Avoidance Decision Making Using a Novel Conflict Paradigm and Multivariate Functional Magnetic Resonance Imaging.". The Journal of neuroscience : the official journal of the Society for Neuroscience 35 (45): 15039-49. doi:10.1523/jneurosci.1915-15.2015. PMID 26558775.

66. Ito, R; Lee, AC (15 October 2016). "The role of the hippocampus in approach-avoidance conflict decision-making: Evidence from rodent and human studies.". Behavioural Brain Research 313: 345-57. doi:10.1016/j.bbr.2016.07.039. PMID 27457133.

67. Buzsáki, G (2006). Rhythms of the Brain. Oxford University Press. ISBN 019-530106-4.

68. Buzsáki G, Chen LS, Gage FH (1990). "Spatial organization of physiological activity in the hippocampal region: relevance to memory formation". Progress in Brain Research. Progress in Brain Research 83: 257-68. doi:10.1016/S0079-6123(08)61255-8. ISBN 9780444811493. PMID 2203100.

69. Skaggs WE, McNaughton $B L$, Permenter M, Archibeque $M$, Vogt J, Amaral DG, Barnes CA (Aug 2007). "EEG sharp waves and sparse ensemble unit activity in the macaque hippocampus". Journal of Neurophysiology 98 (2): 898-910. doi:10.1152/jn.00401.2007. PMID 17522177.

70. Buzsáki G (Jan 2002). "Theta oscillations in the hippocampus" (PDF). Neuron33 (3): 325-40. doi:10.1016/S0896-6273(02)00586-X. PMID 11832222.

71. Lubenov EV, Siapas AG (May 2009). "Hippocampal theta oscillations are travelling waves". Nature 459 (7246): 534-9. doi:10.1038/nature08010. PMID 19489117.

72. Komisaruk, B. R. (1970). "Synchrony between limbic system theta activity and rhythmical behavior in rats". Journal of comparative and physiological psychology70 (3): 482.

73. Cantero JL, Atienza M, Stickgold R, Kahana MJ, Madsen JR, Kocsis B (Nov 2003). "Sleep-dependent theta oscillations in the human hippocampus and neocortex". The Journal of Neuroscience 23 (34): 10897-903. PMID 14645485
74. Vanderwolf, C.H (1969). "Hippocampal electrical activity and voluntary movement in the rat". Electroencephalography and Clinical Neurophysiology 26 (4): 407-418. doi:10.1016/0013-4694(69)90092-3. ISSN 00134694.

75. Huerta PT, Lisman JE (Aug 1993). "Heightened synaptic plasticity of hippocampal CA1 neurons during a cholinergically induced rhythmic state". Nature 364 (6439): 723-5. doi:10.1038/364723a0. PMID 8355787.

76. Kahana MJ, Seelig D, Madsen JR (Dec 2001). "Theta returns". Current Opinion in Neurobiology 11 (6): 739-44. doi:10.1016/S0959-4388(01)002781. PMID 11741027

77. Buzsáki G (Nov 1986). "Hippocampal sharp waves: their origin and significance". Brain Research 398 (2): 242-52. doi:10.1016/00068993(86)91483-6. PMID 3026567.

78. Wilson MA, McNaughton BL (Jul 1994). "Reactivation of hippocampal ensemble memories during sleep". Science 265 (5172): 676-79. doi:10.1126/science.8036517. PMID 8036517.

79. Jackson JC, Johnson A, Redish AD (Nov 2006). "Hippocampal sharp waves and reactivation during awake states depend on repeated sequential experience". The Journal of Neuroscience 26 (48): 12415-26. doi:10.1523/JNEUROSCI.4118-06.2006. PMID 17135403.

80. Sutherland GR, McNaughton B (Apr 2000). "Memory trace reactivation in hippocampal and neocortical neuronal ensembles". Current Opinion in Neurobiology 10 (2): 180-86. doi:10.1016/S0959-4388(00)00079-9. PMID 10753801.

81. Buzsáki G (1989). "Two-stage model of memory trace formation: a role for "noisy" brain states". Neuroscience 31 (3): 551-70. doi:10.1016/03064522(89)90423-5. PMID 2687720.

82. Girardeau, Gabrielle; Karim Benchenane; Sidney I Wiener; György Buzsáki; Michaël B Zugaro (September 2009). "Selective suppression of hippocampal ripples impairs spatial memory". Nature Neuroscience 12 (10): 1222-1223. doi:10.1038/nn.2384. PMID 19749750.

83. Ego-Stengel, Valérie; Matthew A. Wilson (January 2010). "Disruption of ripple-associated hippocampal activity during rest impairs spatial learning in the rat". Hippocampus 20 (1): 1-10. doi:10.1002/hipo.20707. PMID 19816984. PMC 2801761

84. Kovacs KA, O'Neill J, Schoenenberger P, Penttonen M, Ranguel Guerrero DK, Csicsvari J (19 Nov 2016). "Optogenetically Blocking Sharp Wave Ripple Events in Sleep Does Not Interfere with the Formation of Stable Spatial Representation in the CA1 Area of the Hippocampus". PLOS ONE 11: e0164675. doi:10.1371/journal.pone.0164675. PMID 27760158. PMC 5070819.

85. Ramón y Cajal S (1894). "The Croonian Lecture: La Fine Structure des Centres Nerveux". Proceedings of the Royal Society 55 (331-335): 444-68. doi:10.1098/rspl.1894.0063.

86. Hebb DO (1949). Organization of Behavior: a Neuropsychological Theory. New York: John Wiley. ISBN 0-471-36727-3.

87. Bliss TV, Lomo T (Jul 1973). "Long-lasting potentiation of synaptic transmission in the dentate area of the anaesthetized rabbit following stimulation of the perforant path". The Journal of Physiology 232 (2): 33156. doi:10.1113/jphysiol.1973.sp010273. PMID 4727084. PMC 1350458.

88. Malenka RC, Bear MF (Sep 2004). "LTP and LTD: an embarrassment of riches". Neuron 44 (1): 5-21. doi:10.1016/j.neuron.2004.09.012. PMID 15450156.

89. Cooke SF, Bliss TV (Jul 2006). "Plasticity in the human central nervous system". Brain 129 (Pt 7): 1659-73. doi:10.1093/brain/awl082. PMID 16672292

90. Malenka RC, Bear MF (Sep 2004). "LTP and LTD: an embarrassment of riches". Neuron 44 (1): 5-21. doi:10.1016/j.neuron.2004.09.012. PMID 15450156

91. Nakazawa K, McHugh TJ, Wilson MA, Tonegawa S (May 2004). "NMDA receptors, place cells and hippocampal spatial memory". Nature Reviews. Neuroscience 5 (5): 361-72. doi:10.1038/nrn1385. PMID 15100719.

92. Hampel H, Bürger K, Teipel SJ, Bokde AL, Zetterberg H, Blennow K (Jan 2008). "Core candidate neurochemical and imaging biomarkers of Alzheimer's disease". Alzheimer's \& Dementia 4 (1): 38-48. doi:10.1016/j.jalz.2007.08.006. PMID 18631949.

93. Prull MW, Gabrieli JD, Bunge SA (2000). "Ch 2. Age-related changes in memory: A cognitive neuroscience perspective". The handbook of aging and cognition. Erlbaum. ISBN 978-0-8058-2966-2.

94. Prull MW, Gabrieli JD, Bunge SA (2000). "Ch 2. Age-related changes in memory: A cognitive neuroscience perspective". The handbook of aging and cognition. Erlbaum. ISBN 978-0-8058-2966-2.

95. Erickson KI, Voss MW, Prakash RS, Basak C, Szabo A, Chaddock L, Kim JS, Heo S, Alves H, White SM, Wojcicki TR, Mailey E, Vieira VJ, Martin SA, Pence BD, Woods JA, McAuley E, Kramer AF (Feb 2011). "Exercise training increases size of hippocampus and improves memory". Proceedings of the 
National Academy of Sciences of the United States of America 108 (7): 30173022. doi:10.1073/pnas.1015950108. PMID 21282661. PMC 3041121.

96. Joëls M (Apr 2008). "Functional actions of corticosteroids in the hippocampus". European Journal of Pharmacology 583 (2-3): 312-321. doi:10.1016/j.ejphar.2007.11.064. PMID 18275953.

97. Woon FL, Sood S, Hedges DW (Oct 2010). "Hippocampal volume deficits associated with exposure to psychological trauma and posttraumatic stress disorder in adults: a meta-analysis". Progress in NeuroPsychopharmacology \& Biological Psychiatry 34 (7): 1181-1188. doi:10.1016/j.pnpbp.2010.06.016. PMID 20600466.

98. Karl A, Schaefer M, Malta LS, Dörfel D, Rohleder N, Werner A (2006). "A meta-analysis of structural brain abnormalities in PTSD". Neuroscience and Biobehavioral Reviews $30 \quad$ (7): doi:10.1016/j.neubiorev.2006.03.004. PMID 16730374.

99. Wright, IC; Rabe-Hesketh, S; Woodruff, PW; David, AS; Murray, RM; Bullmore, ET (January 2000). "Meta-analysis of regional brain volumes in schizophrenia". The American Journal of Psychiatry 157 (1): 16-25. doi:10.1176/ajp.157.1.16. PMID 10618008.

100. Cho RY, Gilbert A, Lewis DA (2005). "Ch 22. The neurobiology of schizophrenia". Neurobiology of Mental Illness. Oxford University Press US. ISBN 978-0-19-518980-3.

101. Kempton MJ, Salvador Z, Munafò MR, Geddes JR, Simmons A, Frangou S, Williams SC (Jul 2011). "Structural neuroimaging studies in major depressive disorder. Meta-analysis and comparison with bipolar disorder". Archives of General Psychiatry 68 (7): 675-90. doi:10.1001/archgenpsychiatry.2011.60. PMID 21727252. see also MRI database at www.depressiondatabase.org

102. Campbell S, Macqueen G (Nov 2004). "The role of the hippocampus in the pathophysiology of major depression". Journal of Psychiatry \& Neuroscience 29 (6): 417-26. PMID 15644983. PMC 524959.

103. Starkman, MN; Giordani, B; Gebarski, SS; Berent, S; Schork, MA; Schteingart, DE (15 December 1999). "Decrease in cortisol reverses human hippocampal atrophy following treatment of Cushing's disease.". Biological psychiatry 46 (12): 1595-602. PMID 10624540.

104. Disorders, Institute of Medicine (US) Forum on Neuroscience and Nervous System (1 January 2011). "Overview of the Glutamatergic System". National Academies Press (US)

105. Garcia-Segura LM (2009). Hormones and Brain Plasticity. Oxford University Press US. ISBN 978-0-19-532661-1.

106. Conrad CD (2008). "Chronic stress-induced hippocampal vulnerability: the glucocorticoid vulnerability hypothesis". Reviews in the Neurosciences 19 (6): 395-411. doi:10.1515/revneuro.2008.19.6.395. PMID 19317179. PMC 2746750.

107. Ortiz, JB; McLaughlin, KJ; Hamilton, GF; Baran, SE; Campbell, AN; Conrad, CD (29 August 2013). "Cholesterol and perhaps estradiol protect against corticosterone-induced hippocampal CA3 dendritic retraction in gonadectomized female and male rats.". Neuroscience 246: 409-21. PMID 23618757.

108. F, Velasco; D, Trejo; de Oca M, Montes; AL, Velasco (2016). "Neuromodulation of Bilateral Hippocampal Foci, an Alternative for Mesial Temporal Lobe Seizures in Patients with Non-Lesional MRI: Long-Term Follow-up". Epilepsy Journal 02 (04). doi:10.4172/2472-0895.1000116. ISSN 24720895.

109. Kuruba R, Hattiangady B, Shetty AK (Jan 2009). "Hippocampal neurogenesis and neural stem cells in temporal lobe epilepsy". Epilepsy \& Behavior 14 Suppl 1: 65-73. doi:10.1016/j.yebeh.2008.08.020. PMID 18796338. PMC 2654382.

110. Chang BS, Lowenstein DH (Sep 2003). "Epilepsy". The New England Journal of Medicine 349 (13): 1257-66. doi:10.1056/NEJMra022308. PMID 14507951.

111. Sloviter RS (Feb 2005). "The neurobiology of temporal lobe epilepsy: too much information, not enough knowledge". Comptes Rendus Biologies 328 (2): 143-53. doi:10.1016/j.crvi.2004.10.010. PMID 15771000.

112. Harrison PJ (Jun 2004). "The hippocampus in schizophrenia: a review of the neuropathological evidence and its pathophysiological implications". Psychopharmacology 174 (1): 151-62. doi:10.1007/s00213-003-1761-y. PMID 15205886

113. Goto Y, Grace AA (Nov 2008). "Limbic and cortical information processing in the nucleus accumbens". Trends in Neurosciences 31 (11): 552-8. doi:10.1016/j.tins.2008.08.002. PMID 18786735. PMC 2884964.

114. Boyer P, Phillips JL, Rousseau FL, Ilivitsky S (Apr 2007). "Hippocampal abnormalities and memory deficits: new evidence of a strong pathophysiological link in schizophrenia". Brain Research Reviews 54 (1): 92-112. doi:10.1016/j.brainresrev.2006.12.008. PMID 17306884.
115. Ho BC, Andreasen NC, Ziebell S, Pierson R, Magnotta V (February 2011). "Long-term Antipsychotic Treatment and Brain Volumes". Arch. Gen. Psychiatry68: 128-37. doi:10.1001/archgenpsychiatry.2010.199. PMID 21300943. PMC 3476840.

116. Fusar-Poli; Smieskova, $\mathrm{R}_{i}$ Kempton, $\mathrm{MJ}$; $\mathrm{Ho}, \mathrm{BC}_{i}$ Andreasen, $\mathrm{NC}$; Borgwardt, S. (September 2013). "Progressive brain changes in schizophrenia related to antipsychotic treatment? A meta-analysis of longitudinal MRI studies."'. Neuroscience \& Biobehavioral Reviews 37: 1680-1691. doi:10.1016/j.neubiorev.2013.06.001. PMID 23769814. PMC 3964856.

117. Haukvik, UK; Hartberg, CB; Agartz, I (23 April 2013). "Schizophrenia--what does structural MRI show?". Tidsskrift for den Norske laegeforening : tidsskrift for praktisk medicin, ny raekke 133 (8): 850-3. doi:10.4045/tidsskr.12.1084. PMID 23612107.

118. Harrison, PJ; Eastwood, SL (2001). "Neuropathological studies of synaptic connectivity in the hippocampal formation in schizophrenia.". Hippocampus 11 (5): 508-19. doi:10.1002/hipo.1067. PMID 11732704.\}

119. Szabo, K (2014). "Transient global amnesia.". Frontiers of neurology and neuroscience 34: 143-9. doi:10.1159/000356431. PMID 24777137.

120. Lewis SL (Aug 1998). "Aetiology of transient global amnesia". Lancet 352 (9125): 397-9. doi:10.1016/S0140-6736(98)01442-1. PMID 9717945.

121. Chung CP, Hsu HY, Chao AC, Chang FC, Sheng WY, Hu HH (Jun 2006). "Detection of intracranial venous reflux in patients of transient global amnesia". $\quad$ Neurology $66 \quad$ (12): doi:10.1212/01.wnl.0000219620.69618.9d. PMID 16801653.

122. West MJ (1990). "Stereological studies of the hippocampus: a comparison of the hippocampal subdivisions of diverse species including hedgehogs, laboratory rodents, wild mice and men". Progress in Brain Research. Progress in Brain Research 83: 13-36. doi:10.1016/S0079-6123(08)612388. ISBN 9780444811493. PMID 2203095

123. Suzuki M, Hagino H, Nohara S, Zhou SY, Kawasaki Y, Takahashi T, Matsui $\mathrm{M}$, Seto $\mathrm{H}$, Ono $\mathrm{T}$, Kurachi M (Feb 2005). "Male-specific volume expansion of the human hippocampus during adolescence". Cerebral Cortex 15 (2): 187-93. doi:10.1093/cercor/bhh121. PMID 15238436.

124. Jacobs LF (2003). "The evolution of the cognitive map". Brain, Behavior and Evolution 62 (2): 128-39. doi:10.1159/000072443. PMID 12937351.

125. Jacobs LF, Gaulin SJ, Sherry DF, Hoffman GE (Aug 1990). "Evolution of spatial cognition: sex-specific patterns of spatial behavior predict hippocampal size". Proceedings of the National Academy of Sciences of the United States of America 87 (16): 6349-52. doi:10.1073/pnas.87.16.6349. PMID 2201026. PMC 54531.

126. Aboitiz F, Morales D, Montiel J (Oct 2003). "The evolutionary origin of the mammalian isocortex: towards an integrated developmental and functional approach". The Behavioral and Brain Sciences 26 (5): 535-52. doi:10.1017/S0140525X03000128. PMID 15179935.

127. Rodríguez F, López JC, Vargas JP, Broglio C, Gómez Y, Salas C (2002). "Spatial memory and hippocampal pallium through vertebrate evolution: insights from reptiles and teleost fish". Brain Research Bulletin 57 (3-4): 499-503. doi:10.1016/S0361-9230(01)00682-7. PMID 11923018.

128. Colombo M, Broadbent N (Jun 2000). "Is the avian hippocampus a functional homologue of the mammalian hippocampus?". Neuroscience and Biobehavioral Reviews 24 (4): 465-84. doi:10.1016/S01497634(00)00016-6. PMID 10817844.

129. Shettleworth SJ (2003). "Memory and hippocampal specialization in foodstoring birds: challenges for research on comparative cognition". Brain, Behavior and Evolution 62 (2): 108-16. doi:10.1159/000072441. PMID 12937349

130. Nieuwenhuys, R (1982). "An Overview of the Organization of the Brain of Actinopterygian Fishes". Am. Zool. 22 (2): 287-310. doi:10.1093/icb/22.2.287

131. Portavella M, Vargas JP, Torres B, Salas C (2002). "The effects of telencephalic pallial lesions on spatial, temporal, and emotional learning in goldfish". Brain Research Bulletin 57 (3-4): 397-99. doi:10.1016/S03619230(01)00699-2. PMID 11922997.

132. Vargas JP, Bingman VP, Portavella M, López JC (Nov 2006). "Telencephalon and geometric space in goldfish". The European Journal of Neuroscience 24 (10): 2870-78. doi:10.1111/j.1460-9568.2006.05174.x. PMID 17156211

133. Mizunami M, Weibrecht JM, Strausfeld NJ (Dec 1998). "Mushroom bodies of the cockroach: their participation in place memory". The Journal of Comparative Neurology 402 (4): 520-37. doi:10.1002/(SICI)10969861(19981228)402:4<520::AID-CNE6>3.0.CO;2-K. PMID 9862324. 